\title{
Miscarriage and associated risk factors in India: a brief review
}

\begin{abstract}
In India, there is dearth of statistical data on still birth, miscarriage and induce abortion. In addition to this, data on miscarriage on first, second and third trimester among unskilled daily wage women workers is lacking in India. Women even in their early age (20 to 30years) suffers from physical, emotional and social trauma that are associated with still birth, miscarriage or induce abortion. Miscarriage among women workers can be due to multiple factors such as nutrition, environmental factors, occupational factors, individual health status, socio-economic and demographic factors as well as various clinical parameters are associated. Women involved in manual labour with low socio economic status bear triple burden such as domestic, economic and work related responsibility which make them more vulnerable. Women with low socio economic status live in poverty with lack of basic amenities, low wage and lack of social security. In addition to this, there is poor housing, lack of sanitation, unhygienic migratory settlements, lack of safe and potable drinking water, improper nutrition and lack in health facilities making them more vulnerable. Unexpected or unfavorable pregnancy outcomes can be stress full for working women and their families. The research intended to estimate the prevalence of miscarriage among women and to study risk factors associated with it.
\end{abstract}

Keywords: miscarriages, working women, risk factors
Volume 4 Issue 4 - 2017

\section{Geetil Kamble,' Mayuri Banerjee Bhattacharya ${ }^{2}$}

'School of Health and Social Care, Oxford Brookes University, United Kingdom

${ }^{2}$ Department of Public Health, Manipal University, India

\begin{abstract}
Correspondence: Mayuri Banerjee, Master of Public Health in Environment and Occupational Health, Manipal University, Research and Development (Health and Safety), Leela's Foundation for Education and Health [NSDC Partner Institution], Karnataka, India,

Email banerjeemayuri7@gmail.com, bhattacharya.mayuri08@ gmail.com
\end{abstract}

Received: February 10, 2017 | Published: March 06, 2017

\section{Background}

It can be suggested that developing countries, including India, are still racing towards achieving MDG goals 4 and 5. According to UNICEF, ${ }^{1} 800$ women, globally, die every day of preventable causes related to childbirth and pregnancy, out of those, 160 women are from India. Although, maternal mortality rate has been successfully reduced from 197 in the year 2013 to 174 in the year $2015,{ }^{2}$ mothers living in remote areas will still remain at risk of dying in childbirth due to lack of awareness, illiteracy and inappropriate healthcare facilities. On other hand, 1.05 million infant deaths and 0.748 million new born deaths occur every year in India. ${ }^{1}$ In addition, India has consistently displayed efforts in reducing overall child mortality rates. In India, since the year 2013 neo natal mortality rate, infant mortality rate and under 5 mortality rate was 30,41 and 52 respectively, that reduced to 28,38 and 48 in the year $2015 .^{3-5}$ Despite of modest reduction, occurrence of stillbirth is still highest in India indicating rates from 20 to 66 per 1,000 births in different states. ${ }^{6,7}$

It's been acknowledged by technical advisory group (TAG) that in comparison to maternal and post neonatal child mortality, the rate of reduction of new born mortality is slow and it is estimated that the interventions will reduce maternal mortality and saving newborn lives will prevent stillbirths. ${ }^{8}$ It is believed that increase in maternal deaths due to complications of abortions is higher in rural areas because of inappropriate measures in hospitals and unskilled healthcare professionals. In contrast, in India, maternal deaths due to abortion were high in urban than in rural areas. ${ }^{9}$ Still birth, induced abortion and miscarriages can be suggested a public health concern in India. Furthermore, lack of notification and unidentified cases could hamper progress of the country and will drive away from the target to conquer the MDG 4 and 5 .

\section{Global scenario}

Globally, with more than 7178 deaths a day, there were 2.6million stillbirths in the year $2015^{10,11}$ with three quarters in south Asia and sub Saharan Africa, half of still births occur during labour-about 1.3 million each year and $60 \%$ occur in rural areas and more than 40 million women give birth unattended at home each year. WHO, ${ }^{10}$ claims that majority of still births occur in developing countries. Furthermore, half of all stillbirths occur in India, Nigeria, Pakistan, Bangladesh and China alone and reflect for highest number of newborn and maternal deaths. ${ }^{6}$ Likewise, the rate of abortion is higher in developing countries than developed countries. ${ }^{12}$ A new study, undertaken during the period 2010-2014, by the Guttmacher Institute and $\mathrm{WHO}$, has estimated that, there were 35 abortions per 1000 women aged between 15-44 signifying an average 56million induced (safe and unsafe) abortions each year. ${ }^{12,13}$ Despite of the legalization, India has highest number of unsafe abortion with two third abortions performed illegally. ${ }^{14}$

Furthermore, out of estimated 42million induced abortions; 20million are performed by unskilled workers or in perilous circumstances and result in approximately 42000 deaths of girls and women. ${ }^{14}$ It is estimated that all unsafe abortions take place in developing countries indicating about 38 million induced abortions out of which 21 million were unsafe and 17 million safe abortions. ${ }^{15}$ According to $\mathrm{WHO}^{12}$ more than 3 million women who have complications following unsafe abortion do not receive care and every year, in developing countries, around 5million women are hospitalized due to unsafe abortion. This signifies a major setback in the economy of the country due to the burden of economic costs utilised in the treatment to prevent complications associated with the unsafe abortions and inevitable deaths in women and child. The projected annual cost for treating complications associated with abortion was $\$$ 680 million. ${ }^{12}$ In addition, a study in India stated that US \$1.5billion 
could be saved by adding safe abortion to family planning efforts. ${ }^{16}$ Furthermore, in comparison to high income country, an African woman has a 24times greater chance of having stillbirth at time of delivery. ${ }^{6}$ It remains argumentative on just how frequently miscarriages occur, with indicated rates as $31 \%{ }^{17}$ and upto $50 \% .^{18} \mathrm{~A}$ study performed in Bihar, India, using a stratified random sampling approach, reported that out of 15,138 women, the number of miscarriages in past 12 months was $788 .{ }^{19}$ Furthermore, the prospective study conducted on Australian women, indicated that 2544 miscarriages occurred in total of 5806 women. $^{20}$

\section{Factors associated with abortion}

Abortion both induced and spontaneous is due to various factors like socio-demographic characteristics such as age, marital status, race, religion, education, occupational status and family income as well as due to individual health and occupational status. ${ }^{21}$ Women with lower socio-economic status are at higher risk of abortion the main reason was unplanned pregnancy. Age is another risk factor associated with abortion. Various international studies revealed that older women are at greater risk of having abortion as compared to the younger women. ${ }^{22}$ Women with risk behaviour are more vulnerable and have higher rate of abortion. Study conducted in Combodia stated that female sex worker suffering from HIV and sexually transmitted diseases opt of abortion. In addition, female sex workers also encounter with unplanned pregnancies due to lack of knowledge and awareness on contraceptive and condom use. ${ }^{23}$ Young female encounter with unplanned or unwanted pregnancy due to low utilization of contraceptive pills as a result induces abortion is high among them. Furthermore, educational status among women related to abortion, uneducated women are risk of unplanned pregnancies which is leading cause of induce abortions. ${ }^{24}$ Epidemiological have shown that occupational exposures have negative outcome on pregnancy as it effect ante natal and prenatal growth of the developing foetus. Women exposed to harmful chemical agents (heavy metals, pesticide, solvents, drugs, ionic and non ionic radiation), physical agents (extreme heat exposure, strenuous work, working is cold), ergonomic conditions (repeated bending movements, prolonged standing postures, heavy lifting work, work schedule and working environment) as well as occupational stress is associated with spontaneous abortions. ${ }^{25}$

\section{Policies}

It is not inevitable to prevent maternal mortality and morbidity unless rational decisions are taken to reduce IMR. Despite of laws legalized on abortions, from the above data it is clear that the deaths among women and child have not shown exponential reduction in their death rates. Studies show that underlying causes for MMR and IMR due to abortions, still births and miscarriages are unskilled healthcare workers and lack of obstetric and gynaecological care and maternal deaths could be averted with safe abortion methods. When trained persons using correct techniques perform induced abortion it is a safe procedure. ${ }^{12}$ On other hand, maternal deaths due to still births reflect low skilled health professional attendants at birth. ${ }^{10}$ Policies are generally focused on planning and management of safe abortions, legal grounds for safe abortion, eliminating regulatory and policy barriers to safe abortion care and treatment of abortion complications. ${ }^{26}$ In India, abortion policy states that the safe abortion can be performed legally only by certified allopathic physicians, gynaecologists and obstetricians. ${ }^{27}$ Similarly, France and Sweden have tried to reduce medical costs by reducing the workload on the physicians by engaging more nurse-midwives. In Great Britain medical abortion services are supervised by nurses with physicians if required. ${ }^{28}$ It can be suggested that regulatory principles and law policies hinders the mid-level professionals to perform abortion procedures. Furthermore, in the USA, over the years, there has been a constant demand by nurse, midwives and physician's assistant for training on abortion; moreover, studies show lack of training among these healthcare professionals. ${ }^{28}$ However, the scenario in South Africa and Vietnam is different as where aspiration abortions can be performed by midlevel providers. Nevertheless, study review by WHO Reproductive Health Library, ${ }^{29}$ claims that for the first trimester medical abortions and first trimester surgical abortions provided by midwives, there was no difference in the risk of failure neither in risk of complications compared to doctors. Similarly, in Nepal, the study conducted by Ipas, ${ }^{30}$ reported that even in remote areas auxiliary nurse midwives (ANMs) successfully performed medical abortion after adequate training. Apart from fighting for the rights in obtaining safe abortion services, women also face stigma associated with abortions which is a grave concern in developing countries, especially, in India. Likewise, Malawian women face social implications of unsafe abortions and unwanted pregnancies ${ }^{31}$ (Figure 1).

\begin{tabular}{|c|c|c|}
\hline $\begin{array}{l}\text { Direct Causes } \\
>\text { Illiteracy } \\
>\text { Lack of Knowledge \& } \\
\text { awareness } \\
>\text { Lack of Health care services } \\
>\text { Cost of Health care } \\
>\text { Lack of Clinical Training } \\
>\text { Lack of Man power in } \\
\text { Health care industry } \\
>\text { Lack of Health Care } \\
\text { Utilization }\end{array}$ & $\begin{array}{c}\text { Unsafe Ab ortion in } \\
\text { India }\end{array}$ & $\begin{array}{l}\text { Indirect Causes } \\
>\text { Economic } \\
>\text { Stigma } \\
>\text { Political } \\
>\text { Lack of resources at } \mathrm{PHC} \\
>\text { Only physicians can } \\
\text { perform abortions } \\
>\text { Law, regulations and } \\
\text { policies } \\
>\text { Vulnerability }\end{array}$ \\
\hline
\end{tabular}

Figure I Influential factors that causes unsafe abortions. 


\section{Conclusion}

There is no denial that miscarriages, still births and abortions remain a public health problem in developing and developed countries. Moreover, development of a robust policy, regulatory principles and laws is the hour of the need today. Despite of several countries managed to control the maternal mortality and morbidity and control the death rate between 0-5 year age group, India is still yet to accomplish the MDG 4 and 5. In India, especially in rural areas, it is essential to educate and create awareness among the vulnerable population by community health workers like Anganwadi (AGW), ANMs and ASHAs, as these health workers are first line of contact in the community, they stay within the vicinity and there are less postings and transfers. Involving stakeholders like community, families, local leaders and media can help to curb stigma about abortions and can assist in promoting safe abortion in the society in equitable manner. In addition, approximately every abortion death and disability could be prevented through use of effective contraception sexuality education, legal induced abortion provision of safe and timely care for complications (WHO, 2016b). With the plausible outcomes, the economic costs and burden associated with unsafe abortions and complications can be reduced and further enhance the progress of the country.

\section{Acknowledgements}

None.

\section{Conflict of interest}

The author declares no conflict of interest.

\section{References}

1. Maternal Health in Focus. USA: UNICEF; 2012.

2. Maternal mortality ratio (modeled estimate, per 100,000 live births). Switzerland: The World Bank group; 2016.

3. Mortality rate, neonatal (per 1,000 live births). Switzerland: The World Bank group; 2016.

4. Mortality rate, infant (per 1,000 live births). Switzerland: The World Bank group; 2016.

5. Mortality rate, under-5 (per 1,000 live births). Switzerland: The Wolrd Bank group; 2016.

6. PMNCH Fact sheet: Stillbirths. The Partnership for Maternal, Newborn and Child Health. Switzerland: WHO; 2016.

7. Bhati DK. Stillbirths: A high magnitude public health issue in India. South East Asia Journal of Public Health. 2014;3(1):3-9.

8. Ending preventable maternal, newborn and child mortality Regional Technical Advisory Group Meeting. Switzerland: WHO; 2015. p. 1-78.

9. Kumar KSB, Behera SM. Abortion complications and the risk of death among Indian women. Presented at the International Seminar on Measure of Abortion Incidence, Abortion-related Morbidity and Mortality, France; 2007. p. 7-9.

10. Maternal, newborn, child and adolescent health. Switzerland: WHO; 2016.
11. Ending preventable stillbirths. The Lancet. USA; 2016. p. 1-8.

12. Preventing unsafe abortion. Switzerland: World health organisation; 2016.

13. Sexual and reproductive health. Switzerland: WHO; 2016.

14. Abortion Facts and Figure. USA: Population Reference Bureau; 2011. p. $1-64$.

15. Safe and unsafe induced abortion. Switzerland: WHO; 2012. p. 1-8.

16. Goldie SJ, Sweet S, Carvalho N, et al. Alternative strategies to reduce maternal mortality in india: a cost-effectiveness analysis. PLoS Med. 2010;7(4):e1000264

17. Wilcox AJ, Weinberg CR, O'Connor JF, et al. Incidence of early loss of pregnancy. N Engl J Med. 1988;319(4):189-194.

18. El Sayed MM, Mohamed SA, Jones MH. Expectant management of first-trimester miscarriage. Journal of Obstetrics and Gynaecology. 2009;29(8):681-685.

19. Kochar PS, Dandona R, Kumar GA, et al. Population-based estimates of still birth, induced abortion and miscarriage in the Indian state of Bihar. BMC Pregnancy Childbirth. 2014;14:413.

20. Hure AJ, Powers JR, Mishra GD, et al. Miscarriage, preterm delivery, and stillbirth: large variations in rates within a cohort of australian women. PLoS One. 2012;7(5):e37109.

21. Santos APV, Coelho EAC, Gusmão MEN, et al. Factors associated with abortion in women of reproductive age. Rev Bras Ginecol Obstet. 2016;38(6):273-279.

22. Souza MG, Fusco CL, Andreoni SA, et al. Prevalence and sociodemographic characteristics of women with induced abortion in a population sample of São Paulo, Brazil. Rev Bras Epidemiol. 2014;17(2):297-312.

23. Sopheab H, Tuot S, Chhea C, et al. Characteristics, risk behaviours and factors associated with abortion among female entertainment workers in Cambodia. Reprod Health. 2015;12:82.

24. Mote CV, Otupiri E, Hindin MJ. Factors associated with induced abortion among women in hohoe, Ghana. Afr J Reprod Health. 2010;14(4):110-116.

25. Figà Talamanca I. Occupational risk factors and reproductive health of women. Occup Med (Lond). 2006;56(8):521-531.

26. Safe abortion: Technical \& policy guidance for health systems. Switzerland: World Health organisation; 2015. p. 1-10.

27. Stillman M, Frost JJ, Singh S, et al. Abortion in India: A Literature Review USA: Guttmacher Institute; 2014. p. 1-48.

28. Berer M. Provision of abortion by mid-level providers: international policy, practice and perspectives. Bull World Health Organ. 2009;87(1):58-63.

29. The WHO Reproductive Health Library (RHL) is a curated collection of high-quality evidence in reproductive health, published by the World Health Organization. Switzerland: World Health Organization; 2016.

30. Nepal study finds auxiliary nurse midwives can successfully provide medical abortion care. Ipas, India; 2016.

31. Levandowski BA, Kalilani Phiri L, Kachale F, et al. Investigating social consequences of unwanted pregnancy and unsafe abortion in Malawi: The role of stigma. Int J Gynaecol Obstet. 2012;118 Suppl 2:S167-171. 